\title{
Erratum to: Safety of zidovudine/lamivudine scored tablets in children with HIV infection in Europe and Thailand
}

The European Pregnancy and Paediatric HIV Cohort Collaboration (EPPICC) study group in EuroCoord

Published online: 15 February 2017

(C) Springer-Verlag Berlin Heidelberg 2017

Erratum to: Eur J Clin Pharmacol

DOI 10.1007/s00228-016-2182-2

The original publication of the paper contains a mistake.

There should be no author name present in the article.

The original article was corrected.

The online version of the original article can be found at http://dx.doi. org/10.1007/s00228-016-2182-2.

a.judd@ucl.ac.uk;

1 MRC Clinical Trials Unit at UCL, Institute of Clinical Trials and Methodology, University College London, Aviation House, 125

Kingsway, London WC2B 6NH, UK 